\title{
DA CONSTRUÇÃO DO CURRÍCULO À APRENDIZAGEM SIGNIFICATIVA: A PRÁTICA DOCENTE DE GEOGRAFIA NA EDUCAÇÃO DE JOVENS E ADULTOS
}

\author{
Camila Vianna de Souza ${ }^{1}$ \\ Tiago Dionísio da Silva
}

\begin{abstract}
RESUMO
O trabalho visa apresentar a realidade do contexto educacional contemporâneo da Educação de Jovens e Adultos (EJA) para compreender os estudantes como sujeitos e objetos no processo de ensinoaprendizagem, ou seja, a realidade, os lugares de vivências, suas rotinas e referências culturais são centralidades deste artigo. Desse modo, os professores podem organizar e planejar o currículo para que a construção do conhecimento tenha sentido e significado na vida dos discentes. A pesquisa também apresenta uma análise da estrutura curricular da disciplina de Geografia na modalidade Educação de Jovens e Adultos (EJA) no município de Duque de Caxias, RJ. As discussões presentes neste artigo apontam para a necessidade da reconfiguração do currículo escolar do referido município, e para a relevância de se trabalhar com os conteúdos a partir das práticas socioespaciais dos discentes, pois assim os estudantes podem se (re) conhecer dentro de sua realidade, possibilitando a aprendizagem significativa e tornando o discente um sujeito do processo didático-pedagógico em Geografia.
\end{abstract}

Palavras-chave: Educação de Jovens e Adultos. Aprendizagem Significativa. Currículo. Prática docente em Geografia.

\section{FROM SYLLABUS DESIGN TO MEANINGFUL LEARNING: THE TEACHING OF GEOGRAPHY IN YOUTH AND ADULT EDUCATION}

\begin{abstract}
The work aims to present the reality of the contemporary educational context of Youth and Adult Education (EJA) to understand students as subjects and objects in the teaching-learning process, that is, the reality, the places of experiences, their routines and their references cultural. In this way, teachers can organize and plan the curriculum so that the construction of knowledge has meaning and meaning in the lives of students. The research also presents an analysis of the curricular structure of the Geography discipline in the Youth and Adult Education (EJA) modality in the municipality of Duque de Caxias, RJ. The discussions in this article point to the need to reconfigure the school curriculum of that municipality and the relevance of working with the contents based on the students' socio-spatial practices, as this way students can (re) know themselves within their reality, enabling meaningful learning, making the student the subject of the didactic-pedagogical process in Geography.
\end{abstract}

Keywords: Youth and Adult Education. Meaningful Learning. Curriculum. Teaching practice in Geography.

\footnotetext{
${ }^{1}$ Graduada em Licenciatura Plena em Geografia pela UFRRJ. Mestre em Geografia na linha de Ensino pela UERJ e Doutoranda em Geografia pela mesma Instituição. E-mail: camilaviannageo@gmail.com.

${ }^{2}$ Doutorando e Mestre em Educação pela UFRRJ. Especialista em Educação e Relações Raciais pelo Programa de Estudo Sobre o Negro na Sociedade Brasileira (PENESB/UFF). Especialista em Docência e Educação Básica pela Faculdade de Educação da UFF. Possui Graduação (Licenciatura e Bacharelado) em Geografia pela UFF. Desde 2009 é professor de Geografia da Secretaria de Estado de Educação do Rio de Janeiro (SEEDUC/RJ), mas entre 2015 e 2018, através de seleção interna, atuou como Formador da área de Ciências Humanas na UNIVERSEEDUC/RJ. Atualmente trabalha na Coordenadoria de Articulação e Elaboração de Projetos Educacionais Inovadores (COAEP/SUPPES/SUBPAE/SEEDUC). Atua, principalmente, nos seguintes temas: Educação de Jovens e Adultos Trabalhadores, Relações Raciais na Educação, Ensino/aprendizagem da Geografia e Formação Continuada Docente. E-mail: tiago_dionisio@hotmail.com.br.
} 
Data de submissão: 21.09 .2020

Data de aprovação: 15.12 .2020

\section{INTRODUÇÃO}

O educador tem um papel de suma importância ao instigar, aguçar e estimular o processo de ensino-aprendizagem, isto é, ele é essencial na criação de mecanismos metodológicos diversos que possam abordar a construção da identidade individual e coletiva. Uma dessas maneiras é o trabalho com a realidade da cidade onde se localiza a escola, englobando questões culturais, sociais, econômicas, históricas e ambientais. Para tanto, a compreensão do papel do professor está na sua relação direta com a forma como desenvolve a mediação entre o estudante e o conhecimento, possibilitando o pensamento e a reflexão sobre aquilo que deseja e precisa ensinar para que o estudante, efetivamente, possa aprender.

Dessa forma, o professor de Geografia precisa dialogar com a análise da leitura espacial do mundo, algo que não é tão simples assim, pois requer a construção de maneiras de fazer os estudantes aguçarem suas capacidades críticas. Então, para que isso seja concretizado, a proposta curricular da disciplina de Geografia precisa estar voltada para conteúdos e conceitos que estimulem o desenvolvimento do raciocínio e da espacialidade e que valorizem os alunos como principais sujeitos do processo de ensino-aprendizagem.

A construção crítica do raciocínio geográfico possibilita ao educando o desenvolvimento de um pensamento mais complexo que irá reelaborar e dinamizar as suas relações espaciais. Tal complexidade intelectual permite que o educando compreenda diversas questões como locais-globais relativas à organização de novas estratégias para pensar e analisar os conceitos científicos. Aprender significa oferecer ao sujeito um tipo de conhecimento relevante já existente na estrutura cognitiva de quem aprende. Isto é, para que um novo tipo de conhecimento atinja o sujeito de forma positiva, é necessário que esse conhecimento tenha significado lógico, o qual pode ser apresentado ou descoberto pelo próprio sujeito. Porém, esse conhecimento deve contribuir para a criação de novos significados e corroborar com os já existentes.

A vida cotidiana de muitos desses estudantes está baseada nas suas práticas socioespaciais, nos seus deslocamentos diários adquiridos ao longo do tempo. Os estudantes da Educação de Jovens e Adultos (EJA), em sua maioria, são trabalhadores que trazem consigo uma bagagem de ricas informações sobre as relações de trabalho e as cadeias produtivas e exploratórias. É relevante compreender as práticas socioespaciais da EJA para refletir sobre a aprendizagem significativa com intuito de possibilitar que os alunos discutam a rotina, o cotidiano, a realidade a partir das suas espacialidades, o que pode ser um estímulo importante para o processo de construção dos saberes.

Este artigo apresenta a importância da aprendizagem significativa e como a prática docente influencia diretamente no processo de ensino-aprendizagem, e, por fim, discute a Geografia apresentada no Documento Curricular da Secretaria Municipal de Educação de Duque de Caxias (2012) das etapas IV e V da EJA, utilizada até os dias atuais. Essa discussão possibilita compreender a maneira como o ensino da Geografia pode contribuir para pensar as práticas socioespaciais dos estudantes, de modo que os conteúdos trabalhados pelos docentes possam ser mais significativos. A escolha do município de Duque de Caxias para a realização dessa pesquisa se deu porque o referido município apresenta uma riqueza econômica significativa, porém outros aspectos como saúde, segurança e educação ainda necessitam de muitos investimentos, pois deixam a desejar. 
Figura 1 - Localização do município de Duque de Caxias, RJ

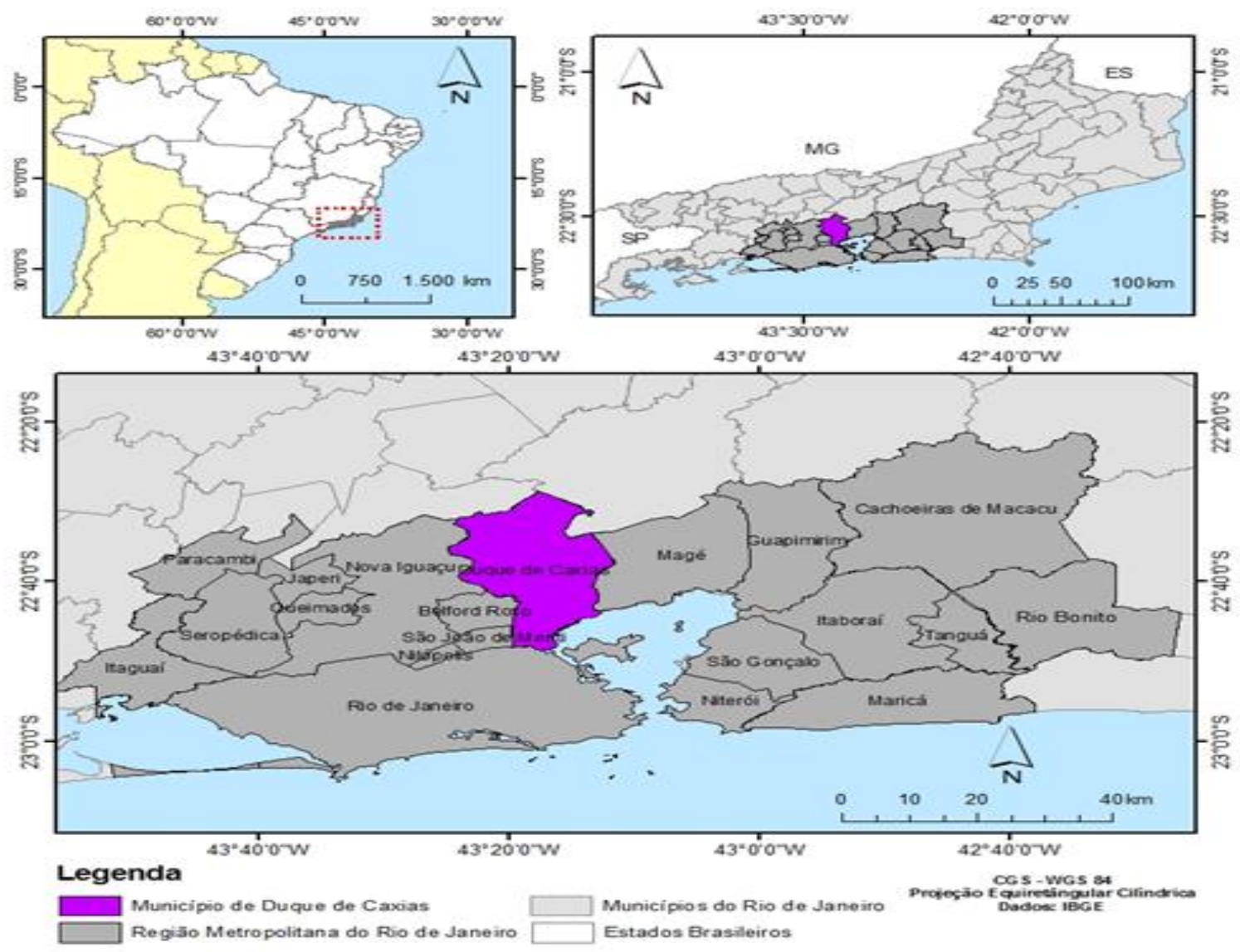

Fonte: Organizado por Seabra (2016, apud SOUZA, 2017, p. 46).

Duque de Caxias está localizada na Região Metropolitana do Rio de Janeiro, na Baixada Fluminense, ocupando uma área de $442 \mathrm{~km}^{2}$. O território está dividido em quatro distritos: $1^{\circ}$ Distrito - Duque de Caxias $\left(41 \mathrm{~km}^{2}\right) ; 2^{\circ}$ Distrito - Campos Elísios $\left(989 \mathrm{~km}^{2}\right) ; 3^{\circ}$ Distrito Imbariê $\left(64 \mathrm{~km}^{2}\right)$ e o $4^{\circ}$ Distrito - Xerém $\left(239 \mathrm{~km}^{2}\right)$. A população do município de acordo com o IBGE (2010) era de 855.048 habitantes, com a estimativa de 924.624 (IBGE, 2020). No território caxiense, são notadas desigualdades sociais bem aparentes, o que deixa patentes os contrastes e as injustiças demográficos.

\section{A APRENDIZAGEM SIGNIFICATIVA COMO PROCESSO DE CONSTRUÇÃO DO CONHECIMENTO GEOGRÁFICO}

A pesquisa em questão almejou trabalhar de forma que o processo de ensinoaprendizagem tivesse relação com a prática social do estudante, objetivando mediar os conhecimentos e conceitos apreendidos ao longo da vida para uma abordagem que buscasse entender conteúdos significativos para os estudantes. Trabalhar a prática social do estudante significa compreender a importância de utilizar o conhecimento já trazido por ele para pensar as diferentes abordagens dos conteúdos escolares, promovendo os conceitos espontâneos e científicos nos quais o estudante aprende a desenvolver suas habilidades intelectuais para a construção de uma aprendizagem dos conteúdos geográficos.

É nesse sentido que o presente estudo pode contribuir para a teoria da aprendizagem significativa, discutidos nos textos de Moraes (2004), Alegro (2008), Tomita (2009), Morais e Cavalcanti (2011). Assim, objetiva-se trazer para o cotidiano um trabalho pedagógico e didático que valoriza os conhecimentos prévios dos discentes como troca de saberes e diálogos, pois a 
aprendizagem significativa é uma teoria que tem como critério abordar o conhecimento atrelado àquilo que já é conhecido pelo sujeito, valorizando suas experiências e mostrando significados no que vai ser aprendido posteriormente. É importante ressaltar que o significativo não está necessariamente relacionado a um novo conhecimento, e sim ao novo sentido que o indivíduo dará ao adquirir outras informações do conhecimento que já tinha, ou seja, fazendo uma interlocução entre a estrutura de conhecimento fomentada pelos conceitos e a cognição.

O professor tem um papel essencial na construção de novas aprendizagens, pois mediante os conteúdos a serem desenvolvidos, é possível fazer as análises da realidade dos estudantes motivando-os a criar possibilidades, argumentações, comparações, de modo que os mesmos consigam trocar experiências, ouvir outros pontos de vista, agregar novas formas de conhecimento, facilitando, assim, a aprendizagem significativa. $\mathrm{O}$ conhecimento pode ser mediado por ambos, tanto o professor quanto os estudantes têm a possibilidade de aprender e construir juntos, afinal todos os indivíduos têm suas próprias histórias. Moraes (2004, p. 60) afirma que: "Nessa perspectiva, a função do educador é gerar atividades por meio de procedimentos concretos que facilitam a motivação para o aprendizado e a de ser um processo de construção do conhecimento". A aprendizagem não pode ser vista como um processo mecânico, por isso o professor, com suas técnicas e metodologias, possibilita ao aluno perceber que os conceitos científicos podem ser incorporados ao seu cotidiano, aplicando nas concepções variadas situações.

No entanto, quando há a ausência de uma formação continuada ou até mesmo exista uma formação inicial precária, o professor apresentará dificuldades para trabalhar determinados conteúdos e conceitos, fazendo com que não haja uma reflexão crítica daquilo que está sendo ensinado; e os discentes passam, então, a ser prejudicados à medida que não são estimulados a refletir. Tomita (2009) afirma que a aprendizagem deve ser significativa, mas, para isso, as experiências e vivências anteriores precisam ser consideradas como fatores relevantes para a construção desse processo. Daí é possível que os alunos consigam compreender melhor e solucionar problemas do seu cotidiano, o que pode ocasionar, ainda de acordo com a autora, novas ações, atitudes e comportamentos e, consequentemente, novas aprendizagens.

\footnotetext{
Nessa expectativa e com base em Ausubel (1980), é recomendável incorporar na prática de ensino, a ideia de que o fator mais importante e que influencia na aprendizagem é aquilo que o aluno já sabe, isto é, a aprendizagem ocorre a partir do que o aluno já conhece e do que já se aprendeu. Assim, no processo de ensinoaprendizagem é importante levar em conta a soma acumulada da educação formal, sistematicamente ocorrida, e também da não formal ocorrida assistematicamente no convívio familiar e social. (TOMITA, 2009, p. 61).
}

O conhecimento científico é um instrumento de "poder" daquele que o detém. De acordo com Moraes (2004), é importante que o indivíduo consiga perceber que a aprendizagem tem um significado e, para que tenha relevância, são necessários quatro fatores:

a) O material disponível aos indivíduos deve ser significativo, de modo que haja relevância em aprender determinado conteúdo, não apenas a memorização de estados e capitais no ensino de Geografia, caso contrário, não haverá uma aprendizagem significativa;

b) O indivíduo necessita ter vontade própria de aprender e também utilizar materiais que podem ser um estímulo maior no processo de aprendizagem. Para ilustrar essa afirmação, citam-se dois exemplos de uma mesma aula de Geografia com a temática de problemas ambientais da cidade: uma em que o professor só ilustra a aula com a sua própria fala, e outra em que há a exposição oral, porém, com o auxílio de vídeo, imagens e comparações de linguagem; 
c) O indivíduo precisa se permitir a aprender novos conhecimentos e, com o auxílio de materiais e métodos, possibilitar ainda mais a apreensão do que já sabe para atrelar ao novo conhecimento;

d) A organização do professor é fundamental, uma vez que ele apresenta oportunidades e várias alternativas para que os alunos possam refletir a partir dos conhecimentos prévios e do novo conhecimento.

Tomita (2009, p. 63) afirma ainda que a "aprendizagem significativa pode ser entendida como uma possibilidade de aprender por caminhos múltiplos, porque envolve a razão pessoal de forma individualizada". A organização dos procedimentos deve estar pautada em objetivos e metodologias bem coerentes aos conceitos, pois assim os estudantes compreendem a função das atividades e são estimulados a refletir. Em vista disso, o professor obterá as respostas expressivas no processo de ensino-aprendizagem.

\section{O CURRÍCULO E A PRÁTICA DOCENTE EM GEOGRAFIA NA EDUCAÇÃO DE JOVENS E ADULTOS}

O currículo é um documento importante para o educador, pois contém os conteúdos que serão supostamente trabalhados ao longo do ano letivo, tendo o professor a possibilidade de selecioná-los. É importante ressaltar que o currículo não é só conteúdo, mas relação de poder, cultura e conhecimento, já que está relacionado à forma como a educação se consolida dentro e fora da sala de aula; às relações entre professor e educando, professor e escola, professor e comunidade; aos conceitos e conteúdos propostos; à forma ideológica que este documento é construído, dentre tantas outras situações às quais o documento se associa. Diante disso, o professor tem um papel importante, pois se faz necessário entender as contradições cotidianas, ter consciência política do seu papel enquanto educador, debater, buscar e romper com as desigualdades e a exclusão social.

É importante ressaltar que as experiências cotidianas dos estudantes não estão necessariamente organizadas no currículo formal a ser seguido, e, por isso, cabe ao docente fazer as articulações dos conteúdos e dos conceitos científicos. Compreender a função social da disciplina de Geografia permite que o conhecimento construído entre professor e aluno em sala de aula seja um instrumento essencial para o processo de aprendizagem, uma vez que, para Kaercher (2003), a Geografia é feita no nosso dia a dia e deve partir do cotidiano do educando, cuja realidade torna-se objeto de reflexão e, assim, deve estar presente na espacialidade costumeira de cada aluno em sua plenitude e complexidade. Assim, o professor, ao organizar seu material para uma determinada aula, tem a possibilidade de criar a disciplina de inúmeras formas, pois, segundo Castrogiovanni (2003), o ensino da Geografia deve priorizar a análise do espaço vivido e oportunizar a compreensão da riqueza espaço-temporal e da própria existência humana. Portanto, neste estudo, incentiva-se o uso das práticas socioespaciais como uma abordagem. Santos (2008, p. 146) afirma: “[...] as práticas sociais, portanto, necessitam de um conhecimento da espacialidade das coisas, um conhecimento geográfico, ainda que não sistematizado".

A prática docente deve ser construída também através da realidade escolar, articulando teoria e prática. Logo, o professor pode aprofundar discussões, trocar experiências, instigar os conhecimentos adquiridos no trabalho, na vida, na escola com o intuito de debater, analisar, questionar, dentro do seu campo disciplinar. Por conseguinte, o educando pode fazer associações com o vivido, fomentando as múltiplas influências sociais presentes nas relações do aluno com a escola e com o mundo. Silva aponta que: 
articulação das disciplinas na escola. Isso não significa desconhecer as decisões políticas que vão desde como o corpo docente é formado, assim como se dá a escolha dos objetivos pedagógicos, quais linguagens serão desenvolvidas assim como os conteúdos (tanto aqueles que os alunos portam como aqueles que são consagrados nas disciplinas). (SILVA, 2012, p. 111).

As atividades didático-pedagógicas produzidas por meio de uma leitura de mundo mais crítica facilitam e contribuem bastante para a construção de conhecimentos, conteúdos e conceitos científicos, pois é o momento em que o educador direciona e possibilita o amadurecimento do raciocínio, o pensamento reflexivo e as manifestações empíricas através do que foi trabalhado teoricamente. Para Cavalcanti,

[...] professores abertos e sensíveis ao diálogo com seus alunos buscam contribuir para o processo de atribuição de significados aos conteúdos trabalhados, baseados em cada contexto específico, de acordo com as representações dos alunos, considerando suas capacidades individuais e de grupo, mas dirigindo o processo a fim de promover a aprendizagem-formação de conceitos - 'adiantando' seu desenvolvimento buscando 'quebrar' barreiras entre conhecimentos científico, escolar e cotidiano. (CAVALCANTI, 2012, p. 173).

Nesse sentido, é necessário ter um conhecimento mínimo da comunidade escolar de forma a reconhecer a espacialidade na qual a escola está inserida, isto é, estar a par das interrelações sociais, físicas, políticas, econômicas, culturais e históricas. Retomando a especificidade da discussão em relação ao currículo, ele é a seleção dos conteúdos produzidos por determinados grupos ou indivíduos baseada numa política educacional. Para Silva,

O currículo é sempre o resultado de uma seleção: de um universo mais amplo de conhecimento e saberes seleciona-se aquela parte que vai construir, precisamente o currículo. As teorias do currículo tendo decidido quais conhecimentos devem ser selecionados, buscam justificar por que 'esses conhecimentos' e não 'aqueles' devem ser selecionados. (SILVA, 1999, p. 15).

O professor tem sua importância na construção e no desenvolvimento do pensamento crítico do discente, por isso torna-se relevante compreender como esse currículo institucional, que muitas vezes vem sendo imposto precisa ser seguido, é apresentado na sala de aula, ou seja, é importante captar como o docente influencia na prática curricular. Segundo Malta,

O currículo tem uma especificidade muito particular. Todos os que dele participam e todos os que têm ingerência sobre o currículo, não o fazem de maneira neutra. Tratase de uma área impregnada de valores, ideologias, forças, interesses e necessidades e exige, para uma definição mais exata, a explicitação de um quadro filosófica, histórica e política. (MALTA, 2013, p. 342).

O currículo tem uma função social, uma vez que nele estão presentes os conteúdos a serem lecionados. Porém, como é feita as seleções desses conteúdos? Existe alguma intencionalidade? Refletindo sobre essas questões, compreende-se que o currículo é um documento de tamanha significância. Silva afirma que:

Da perspectiva pós-estruturalista, podemos dizer que o currículo é também uma questão de poder e que as teorias do currículo, na medida em que buscam dizer o que o currículo deve ser, não podem deixar de estar envolvidas em questões de poder. Selecionar é uma operação de poder. Privilegiar um tipo de conhecimento é uma operação de poder. Destacar, entre as múltiplas possibilidades, uma identidade ou subjetividade como sendo a ideal é uma operação de poder. (SILVA, 1999, p. 16). 
A organização curricular é baseada na concepção de alguns sujeitos ou de um determinado grupo, que através desse documento expressam a sua funcionalidade para o público da EJA. De acordo com Santos:

Isso quer dizer que, ao nos referimos à EJA, devemos levar em conta uma série de complexas relações que envolvem a aquisição de saberes por parte de seu público. Mesmo em programas oficiais de ensino essa dimensão deve ser observada, sem a qual corremos o risco de abandonar toda trajetória histórica percorrida pela tentativa de possibilitar o acesso da classe trabalhadora a outras interpretações e visões de mundo para além daquelas construídas na luta pela sua sobrevivência. (SANTOS, 2008, p. 62).

É importante que, durante as aulas, haja problematização do mundo do trabalho e da própria produção social, de forma que os alunos tenham a possibilidade de refletir a partir das suas vivências cotidianas. Ainda recorrendo a Santos,

A especificidade da EJA enquanto modalidade de ensino voltada para jovens e adultos é atendida quando se articula trabalho, seja em seu sentido social seja em sua dimensão histórica, à produção do espaço. Construir a ideia de que todos são responsáveis por essa produção, inclusive os trabalhadores, embora a sociedade de classes determine papéis e responsabilidades diferenciadas nesse processo, constituise tarefa da geografia escolar para todas as modalidades e níveis de ensino. Na EJA, entretanto, a proporção dessa premissa alcança graus bastante elevados, uma vez que muitos dos alunos já fazem parte do processo produtivo e já têm demarcado seu lugar na divisão social do trabalho, o que os torna ao mesmo tempo testemunhas e agentes de todo o processo estudado. (SANTOS, 2008, p. 279).

Na Educação de Jovens e Adultos, ensinar os conteúdos a partir das vivências dos alunos facilita o processo de ensino-aprendizagem, já que suas práticas socioespaciais são ilustradas. Além disso, as discussões podem ser relevantes para o entendimento do cotidiano e da realidade social dos estudantes. Novamente evocando Santos,

Pode-se dizer que o mundo do trabalho é a temática que mais imediatamente se relaciona com a Educação de Jovens e Adultos. Em uma proposta curricular voltada para essa modalidade, as questões e reflexões sobre o trabalho são praticamente imperativas se pretende atender o princípio através do qual a realidade vivida pelos estudantes deva ser considerada. (SANTOS, 2008, p. 184).

Assim sendo, a problemática do mundo do trabalho e da experiência vivida pelos estudantes da EJA pode ser um elemento na construção de uma proposta curricular de Geografia que privilegie um pensamento autônomo e crítico, bem como das práticas socioespaciais.

\section{A EDUCAÇÃO DE JOVENS E ADULTOS DO MUNICÍPIO DE DUQUE DE CAXIAS E SUA ESTRUTURA CURRICULAR EM GEOGRAFIA}

O currículo do ensino fundamental regular não deve ser comparado ao da EJA, mas revisto e apresentado de maneira distinta, afinal, o público alvo é diferenciado e com isso, tornase inviável fazer qualquer tipo de comparação entre estes dois tipos de educando, pois cada faixa etária corresponde a diferentes fases. Tomando mais uma vez de empréstimo as palavras de Santos:

Se é verdade que devemos respeitar as características desse público ao se pensar um conjunto de provas específicas para ele, é também fato que não devemos entender por isso que a EJA deve ser considerada uma modalidade menor, na qual os conhecimentos escolares devam ser menos prezados ou facilitados. O desafio é 
justamente manter o nível de complexidade exigido no ensino dirigido para crianças e adolescentes, porém adaptado à realidade de vida dessas pessoas. (SANTOS, 2008, p. 150).

Desta forma, o discente conseguiria compreender de maneira mais simplificada a integração entre os conhecimentos escolares e os do cotidiano. De acordo com Santos,

[...] a educação popular só faz sentido quando desenvolvida exatamente na fronteira das disciplinas, o que não quer dizer, obviamente, que os conhecimentos específicos destas não devam ser considerados. Assim, a escolha e o desenvolvimento do tema gerador a partir do universo temático dos alunos exigem conhecimentos espaciais que relacionem o local ao global, ou seja, impõem uma perspectiva que vê o mundo através da articulação das escalas de análise. (SANTOS, 2008, p. 146).

Em relação à disciplina de Geografia, inúmeras foram as reformulações na ciência. Segundo Santos (2008, p. 141): “o objetivo de sintetizar o conteúdo da série escolar ocultava, na verdade, uma geografia tradicional, conservadora e que desprezava o espaço vivido e construído pelos próprios sujeitos participantes das classes supletivas". A Geografia que se encontra presente na escola pode ser entendida a partir da abordagem histórica, sendo justificada por temáticas e questionamentos que são explicados como anacrônicos e ultrapassados.

As transformações que ocorrem no ensino de Geografia na educação básica são consequências das políticas educacionais influenciadas pelas novas abordagens da ciência geográfica, que também está relacionada aos atuais contextos político, econômico e cultural. Diante disso, busca-se mostrar a importância que a Geografia Escolar tem no currículo da EJA, pois, a partir dessa ciência, é possível desenvolver em sala de aula reflexões sobre a vida do aluno trabalhador, auxiliando na criticidade da sua relação com a natureza e dos seus processos históricos, sociais, econômicos e culturais. Conforme Santos:

[...] na seleção de conteúdos normalmente encontrada em livros didáticos e propostas curriculares para a Educação Básica, o mundo do trabalho sempre foi tratado como algo não muito propício a ser aprofundado nas aulas de geografia. É nesse sentido que ações pedagógicas na EJA podem contribuir para a centralidade dessa categoria na perspectiva geográfica. Em função disso, novos conteúdos passam a compor o temário geográfico escolar, dentre eles a maior atenção à geografia do trabalho. (SANTOS, 2011, p. 102).

A disciplina de geografia no currículo escolar auxilia na construção de um pensamento autônomo, reflexivo e pode até mesmo proporcionar um raciocínio espacial do estudante da EJA a partir de suas vivências, sejam elas como discente ou como trabalhador. Neste artigo, apresenta-se parte do currículo do ensino fundamental II, que está presente no Documento Oficial da Secretaria Municipal de Educação de Duque de Caxias (2012), para a EJA. Segundo o documento, a criação do currículo surgiu a partir de consultas realizadas junto à secretaria e aos professores de Geografia dos cursos de EJA. A intenção, portanto, é analisar esse currículo por meio dos objetivos gerais da disciplina de Geografia e dos objetivos específicos das etapas IV (sexto e sétimo anos) e V (oitavo e nono anos), saber como os conteúdos estão organizados e se há algum tipo de temática referente à cidade local ou se apenas seguem as orientações propostas pelo Ministério da Educação (MEC). Na tabela a seguir, estão os objetivos gerais do ciclo da disciplina de Geografia. 
Tabela 1 - Objetivos Gerais da disciplina de Geografia do município de Duque de Caxias

\section{Objetivos Gerais de Geografia}

Redimensionar o entendimento de mundo a partir dos conceitos geográficos básicos, tais como: território, lugar, paisagem, espaço geográfico.

Compreender a diversidade socioespacial, percebendo a importância de respeitá-la.

Compreender a cidadania como parte das relações entre a sociedade e a natureza integrando-se como sujeito ativo, construtor/transformador de seu espaço histórico e cultural.

Desenvolver a autonomia do aluno para que ele busque o conhecimento em diferentes tipos de linguagem.

Compreender a importância das diferentes linguagens (gravuras, músicas, literaturas, dados estatísticos, documentos de diferentes fontes, mapas, gráficos e tabelas) na leitura da paisagem, tornando-se capaz de interpretar, analisar e relacionar diversas informações sobre o espaço.

Utilizar a linguagem gráfica para obter informações, compreendendo a espacialidade dos fenômenos geográficos.

Fonte: Organizado pelos autores baseados na Secretaria Municipal de Educação de Duque de Caxias (2012).

O primeiro objetivo enfatiza a importância dos conceitos geográficos, sendo esses conceitos-chaves. Porém, é relevante incluir o conceito de região não citado no documento, pois esta parte da discussão sobre a disciplina permite compreender as diferentes organizações espaciais a partir de diversas formas de estruturação do território econômico, social, político e cultural, dentre outros âmbitos.

O segundo objetivo, apesar de trazer a questão relacionada à "diversidade socioespacial", não explica quais seriam os grupos ou o tipo de diversidade aos quais faz referência: quilombolas, ribeirinhos, indígenas, entre outros. Não é um objetivo direto, ficando aberto a diferentes interpretações para os professores.

$\mathrm{O}$ terceiro objetivo propõe o resgate da importância da cidadania na relação homem $\mathrm{X}$ natureza e do sujeito como ativo e transformador do espaço geográfico. Estudar cidadania na EJA é importante, pois o educador é capaz de auxiliar na criticidade sobre o direito de ir e vir, na construção do pensamento do que é viver dignamente com acesso à educação e à saúde de qualidade, à segurança, ao saneamento básico, à luz e à água encanada. Logo, essa discussão é relevante para o conhecimento do cidadão.

O quarto objetivo poderia ser substituído porque não destaca nenhum elemento geográfico coerente. E trabalhar com linguagens é parte do sistema operacional pedagógico. Os objetivos quinto e sexto fazem parte também do sistema operatório não apresentando conteúdo pertinente à disciplina de Geografia, pois eles integram as competências. Apesar de compreender a importância da análise das diferentes linguagens para ensinar Geografia, bem como dos diferentes documentos, entende-se que não só a paisagem pode ser analisada a partir dessas linguagens.

Os objetivos gerais presentes no currículo do município de Duque de Caxias são relevantes para a disciplina escolar. Entretanto, temáticas referentes ao cotidiano que privilegia as práticas socioespaciais dos estudantes da EJA poderiam estar incluídas no referido documento. O currículo seguido é o formal, que não tem de fato uma proposta para esse público. Para Resende:

Uma geografia assim concebida leva-nos fatalmente a considerar o aluno, em especial aquele oriundo das classes populares, como um ser neutro, sem vida, sem cultura, sem história - um ser que não trabalha, não produz a riqueza neste momento histórico e neste espaço geográfico determinado. $\mathrm{O}$ aluno não participa do espaço geográfico que ele estuda. Se o espaço não é encarado como algo em que o homem (aluno) está inserido, natureza que ele próprio ajuda a moldar, a verdade geográfica do indivíduo se perde e a Geografia se torna alheia para ele. (RESENDE, 1986, p. 18). 
Existe a necessidade de maior investimento na sistematização e na organização do currículo para a Educação de Jovens e Adultos. O trabalho pedagógico demanda comprometimento e uma produção própria de material didático, de maneira que os alunos sejam capazes de problematizar o que vivenciam, de criar o gosto por estar na sala de aula, de fazer relações e comparações para que o processo de aprendizagem seja contínuo.

Nos objetivos específicos apresentados na tabela 2, serão apontadas explicações de como esse currículo poderia incluir conteúdos e temáticas que partilhassem a experiência e o cotidiano dos alunos.

Tabela 2 - Objetivos Específicos da Etapa IV da disciplina de Geografia do município de Duque de Caxias

\begin{tabular}{l}
\hline \multicolumn{1}{c}{ Objetivos Específicos } \\
\hline Conhecer os conceitos fundamentais que se relacionam aos temas específicos da geografia. \\
\hline Compreender os principais movimentos da Terra e suas influências sobre as atividades humanas. \\
\hline Desenvolver o uso da linguagem cartográfica. \\
\hline Compreender a dinâmica dos fatores internos e externos que afetam o relevo terrestre. \\
\hline Compreender as diferentes formas de regionalização do espaço geográfico brasileiro. \\
\hline Conhecer os diferentes setores da atividade econômica. \\
\hline Compreender a relação existente entre os processos de industrialização e urbanização. \\
\hline Reconhecer os indicadores da desigualdade social no Brasil decorrentes do processo de urbanização das grandes \\
cidades. \\
\hline Compreender as especificidades dos espaços urbano e rural. \\
\hline Compreender os diferentes aspectos relacionados à dinâmica populacional brasileira. \\
\hline Fonte: Secretaria Municipal de Educação de Duque de Caxias, 2012, organizado pelos autores.
\end{tabular}

O primeiro objetivo aponta para a importância de conhecer os conceitos fundamentais da disciplina que já estão especificados nos objetivos gerais. O segundo, terceiro e quarto objetivos atendem aos conteúdos propostos para o $6^{\circ}$ ano, embora ainda que estejam de forma bem resumida. Dentre uma gama de conteúdo, realizou-se uma seleção enfatizando os movimentos da terra, linguagens cartográficas e relevo terrestre.

A linguagem cartográfica é fundamental para localização, orientação, interpretações de informações contidas em mapas, plantas, croquis, entre outros exemplos. Do mesmo modo, é necessário o conhecimento acerca do relevo, pois o aluno não precisa compreender o processo através da utilização de termos técnicos, como a orogênese, mas entender os tipos e formas para articular, por exemplo, com as inundações, com o formato de relevo encontrado na Baixada Fluminense e com suas características e especificidades.

Esses conteúdos geográficos são relevantes para a disciplina, porém, nota-se que o mundo do trabalho não está inserido nos objetivos. Dessa maneira, não há reflexão sobre a vida do aluno trabalhador. Para Santos:

\begin{abstract}
A problemática e a análise do mundo do trabalho, portanto, devem se constituir em ações educativas fundamentais para uma proposta curricular que considere a ressignificação do saber, da experiência e a construção de um pensamento crítico e autônomo por parte dos alunos. Sem dúvida alguma, isso torna extremamente desafiador o trabalho docente e exige dos conhecimentos disciplinares a busca pela melhor forma de contribuir para esse processo, pois nem sempre a tradição seletiva do currículo das escolas para crianças contempla temas, abordagens e exemplos do mundo do trabalho. (SANTOS, 2011, p. 100).
\end{abstract}

Por esse motivo, o papel da Geografia no âmbito escolar da EJA precisa ser repensado com o intento de trazer para a sala de aula conteúdos significativos daquilo que é ensinado, possibilitando a problematização e a experiência do mundo do trabalho que são instrumentos para a construção do pensamento geográfico. Como os demais objetivos dessa etapa são correspondentes ao $7^{\circ}$ ano, entende-se que os mesmos foram bem específicos ao trabalharem o 
espaço brasileiro, pois destacaram as diferentes regionalizações, não enfatizando qual tipo, ou seja, sem ressaltarem se era a subdivisão do IBGE, do Milton Santos, das Regiões Geoeconômicas, entre outras; mesmo apresentadas, essas regionalizações estão na categoria dos objetivos específicos.

Por isso, retoma-se o discurso anterior: será que realmente esses conteúdos não poderiam ser trabalhados de outra maneira, levando em consideração, por exemplo, a contribuição das experiências do estudante, como o relato de um possível deslocamento migratório para o Sudeste? Por que não trabalhar o espaço brasileiro a partir da relação com o mundo do trabalho, fazendo uma abordagem espacial baseada nas cidades? É pautado nesse tipo de temática e conteúdo que o professor da EJA pode criar mecanismos para que o discente sinta-se motivado a participar, contribuir com suas experiências e se interessar pelo que está sendo desenvolvido. Para Resende,

Acreditamos, isto sim, em assumir, dentro do sistema formal de ensino, o papel de agente de contradição, acumulando, através de uma prática ainda que só parcialmente inovadora e mesmo setorizada, forças que podem articular-se, ao nível de luta social concreta, com o avanço das reivindicações política dos trabalhadores por um outro sistema de ensino, por uma verdadeiramente nova, por uma nova sociedade. (RESENDE, 1986, p. 166).

É necessário que a escola cumpra seu papel criando mecanismos para que a educação seja acessível ao público que a frequenta em diferentes turnos. É preciso que o conhecimento se torne acessível às camadas populares de forma a minimizar os impactos sofridos diariamente por sua realidade. Os demais objetivos apresentam conteúdos como: economia brasileira, industrialização, urbanização, desigualdades sociais, o urbano e o rural e dinâmicas populacionais. Desta forma, pode-se afirmar que, entre os conteúdos do $6^{\circ}$ e $7^{\circ}$ anos, há uma significativa parcela de temáticas voltadas para o espaço brasileiro em que o aluno terá a possibilidade de conhecer as relações existentes no seu país.

Todavia, não se ressaltou a questão da especificidade do Estado do Rio de Janeiro e de Duque de Caxias, por exemplo. Será que realmente os estudantes da Educação de Jovens Adultos conhecem minimamente a sua realidade, o seu bairro, a sua cidade ou o seu estado? De modo a obter resultados positivos no processo de ensino-aprendizagem, o educando precisa compreender que o seu cotidiano também faz parte desse dinamismo, sendo possível extrair dele conhecimentos que podem ser desenvolvidos na sala de aula.

Nesse sentido, o professor pode mediar as práticas socioespaciais dos discentes, a geografia do trabalho, a geografia da percepção, voltando-se às temáticas trabalhadas na sala de aula para que o conhecimento seja uma troca, para que o saber científico seja construído coletivamente.

Tabela 3 - Objetivos Específicos da Etapa V da disciplina de Geografia do município de Duque de Caxias

\section{Objetivos Específicos}

Compreender a interação sociedade-natureza e as questões relacionadas aos problemas socioambientais. Compreender as diferentes formas de regionalização do mundo contemporâneo.

Compreender os mais importantes aspectos do processo de globalização.

Analisar a inserção do espaço Latino-Americano na lógica mundial do sistema capitalista.

Analisar a posição da África no Mundo Contemporâneo e a influência de sua cultura na sociedade brasileira. Compreender questões relevantes no continente asiático: conflitos no Oriente Médio e o desenvolvimento da China.

Analisar a crise do Estado de Bem-Estar Social e os conflitos sociais e étnico-religiosos no continente europeu. Fonte: Organizado pelos autores baseados na Secretaria Municipal de Educação de Duque de Caxias (2012). 
Em relação aos objetivos da etapa $\mathrm{V}$, partilham-se conteúdos do $8^{\circ}$ e $9^{\circ}$ anos. $\mathrm{O}$ primeiro objetivo ressalta a relação sociedade-natureza e os problemas socioambientais, porém, mais uma vez, não faz menção à realidade do aluno, sendo este um tema de suma relevância. Assim, observar-se a partir da análise da tabela 3 que a realidade socioambiental do município de Duque de Caxias não está contemplada no currículo. Nesse sentido, vale indagarmos: por que não apresentar aos discentes a relação da cidade local com os problemas socioambientais? Isto é, o Aterro Metropolitano que encerrou as atividades, a relação da Refinaria, a construção do Arco Metropolitano, por exemplo. Dessa forma, cabe ao professor fazer a articulação com o currículo, trazendo novas possibilidades a partir de diferentes escalas que podem partir do localglobal ou vice-versa.

Os demais objetivos trazem os conteúdos a serem seguidos pelos Parâmetros Curriculares Nacionais (PCN) de Geografia (1998), como regionalização mundial, globalização e suas relações com os continentes americano, africano, asiático e europeu. É notória a preocupação em trazer as regionalizações mundiais nessa etapa, apresentando uma visão dos continentes de forma geral. O interessante é que não há a discussão do conceito de região no objetivo geral, como já foi mencionado anteriormente.

Compreender a realidade dos outros continentes é importante para discutir e analisar questões sociais, econômicas, culturais, físicas, inclusive fazendo comparações com o espaço de vivência dos alunos, porém, se os alunos não têm o conhecimento da realidade local, não será possível fazer considerações em âmbito global. De acordo com Resende (1986, p. 156), se "o espaço vivido é sempre descrito e/ou julgado à luz da experiência concreta de trabalho e sobrevivência, à luz da posição que o sujeito ocupa nas relações sociais de produção [...]", o saber geográfico pode estar "escondido" nas experiências que fazem parte da história real dos alunos. Diante disso, mostra-se relevante trazer uma concepção pedagógica que valorize as experiências do aluno e acredite na construção do conhecimento a partir das suas práticas socioespaciais.

\section{CONSIDERAÇÕES FINAIS}

O professor como mediador do processo educativo, de forma didática, tem a possibilidade de inserir os conteúdos curriculares relacionando-os ao contexto do estudante. A compreensão do lugar e do cotidiano levam o aluno à reflexão e ao próprio entendimento do seu papel dentro daquela localidade. Trabalhar a realidade deve ser algo indispensável e mostra a preocupação do educador em querer que seu discente se (re) conheça dentro de sua realidade, possibilitando a aprendizagem significativa.

A organização do currículo deve estar voltada para conteúdos que estimulem o desenvolvimento do raciocínio e da espacialidade, que valorizem o estudante como principal sujeito do processo de ensino-aprendizagem e que sejam construídos politicamente como um saber poderoso, crítico e reflexivo a ser passado, e não como um saber elitizado. O documento curricular do município de Duque de Caxias poderia destacar, na introdução do texto, informações sobre a disciplina de Geografia, sobre a relevância de se trabalhar com os conteúdos a partir das práticas socioespaciais dos estudantes. Desse modo, seria possível reforçar a necessidade de articulação entre a prática pedagógica do professor e a teoria e a prática. Então, cabe ao professor a responsabilidade de trazer determinados conteúdos que possibilitem aos educandos a compreensão da sua realidade, com exemplos da sua cidade e do seu espaço de vivência. As práticas socioespaciais são componentes importantes para compreender o modo de vida dos alunos, suas representações e sua identidade.

Para Sacramento e Souza (2016, p. 13): "Dessa forma, o ensino de Geografia está estritamente ligado à formação da cidadania, pois constrói e reconstrói conhecimentos", capacitando os alunos a terem uma noção do mundo em que vivem, consciência essa que 
configura uma das instâncias formadoras da cidadania, que são as práticas cotidianas. A partir dessa concepção, a escola tem sua responsabilidade na discussão sobre o significado da cidadania que se faz presente na vida do aluno através da organização social e democrática e das lutas e incorporações dos direitos sociais.

A EJA da Educação Básica está associada a um público que possui experiências próprias de vida, presentes no mundo do trabalho. Conforme Resende (1986, p. 20), "agir assim significaria, contudo, valorizar uma experiência de espaço do aluno, do aluno pobre - uma experiência de espaço que lhe é própria”.

\section{REFERÊNCIAS}

ALEGRO, Regina Célia. Conhecimento prévio e aprendizagem significativa de conceitos históricos no Ensino Médio. 2008. Tese (Doutorado em Educação) - Universidade Estadual Paulista Julio de Mesquita Filho, (Campus de Marília), São Paulo, 2008. 239folhas.

BRASIL. Secretaria de Educação Fundamental. Parâmetros Curriculares Nacionais: terceiro e quarto ciclos do ensino fundamental: introdução aos parâmetros curriculares nacionais. Brasília: MEC, 1998.

CASTROGIOVANNI, Antonio Carlos. E agora, como fica o ensino da geografia com a globalização? In: CASTROGIOVANNI, A. C. et al (rg.). Geografia em sala de aula: práticas e reflexões. 4. ed. Porto Alegre: EdUFRGS, 2003. p. 83-85.

CAVALCANTI, Lana de Souza. O ensino de geografia na escola. Campinas: Papirus, 2012.

INSTITUTO BRASILEIRO DE GEOGRAFIA E ESTÁTISTICA. IBGE Cidades.

Disponível em: https://cidades.ibge.gov.br. Acesso em: 12 de ago. 2020.

KAERCHER, Nestor André. A geografia é o nosso dia-a-dia. In: CASTROGIOVANNI, Antonio Carlos. et al (org.). Geografia em sala de aula: práticas e reflexões. 4. ed. Porto Alegre: EdUFRGS, 2003. p. 11-21.

MALTA, Shirley Cristina Lacerda. Uma abordagem sobre currículo e teorias afins visando à compreensão e mudança. Revista Espaço do Currículo, João Pessoa, v. 6, n. 2, p. 340-354, 2013. Disponível em: https://periodicos.ufpb.br/ojs/index.php/rec/article/view/3732/9757. Acesso em: 14 de fev. de 2016.

MORAES, Jerusa Vilhena de. A construção do conceito geográfico por meio do uso de documentos. 2004. Dissertação (Mestrado em Geografia) - Faculdade de Filosofia, Letras e Ciências Humanas da Universidade de São Paulo, São Paulo, 2004.

MORAIS, Eliana Marta Barbosa Vieira; CAVALCANTI, Lana de Souza. A cidade, os sujeitos e suas práticas espaciais cotidianas. In: MORAIS, Eliana Marta Barbosa Vieira; CAVALCANTI, Lana de Souza (org.). A cidade e seus sujeitos. Goiânia: Vieira, 2011. p. 13-30.

RESENDE, Márcia Spyer. A geografia do aluno trabalhador. São Paulo: Loyola, 1986.

SACRAMENTO, Ana Claudia Ramos; SOUZA, Camila Vianna de. A produção social do espaço e o ensino de geografia na cidade de São Gonçalo. Revista da Pós Graduação em 
Geografia-ProPGeo da Universidade Estadual do Ceará, Fortaleza, v. 5, n. 8, p. 6-32, 2016. Disponível em:

$\mathrm{http}: / /$ seer.uece.br/?journal=geouece $\&$ page $=$ article $\&$ op $=$ view $\&$ path $\% 5 \mathrm{~B} \% 5 \mathrm{D}=1608$. Acesso em: 02 de jan. de 2017.

SANTOS, Enio José Serra dos. Educação geográfica de jovens e adultos trabalhadores: concepções, políticas e propostas curriculares. 2008. Tese (Doutorado em Educação) Programa de Pós-Graduação em Educação, Universidade Federal Fluminense, Niterói, 2008.

SANTOS, Enio José Serra dos. A educação geográfica de jovens e adultos trabalhadores no contexto urbano. In: CAVALCANTI, Lana de Souza; BUENO, Miriam Aparecida; SOUZA, Vanilton Camilo de (org.). Produção do conhecimento e pesquisa no ensino da geografia. Goiás: PUC, 2011. p. 97-110.

SECRETARIA MUNICIPAL DE EDUCAÇAO DE DUQUE DE CAXIAS. Proposta pedagógica. 2012. Disponível em: http://www.smeduquedecaxias.rj.gov.br. Acesso em: 16 de abr. 2016.

SILVA, Jorge Luiz Barcellos da. Formação de professores dos anos iniciais do ensino fundamental: considerações sobre escola, conhecimento, linguagem e ensino de Geografia. Terra Livre, São Paulo, v. 1, n. 38, p. 99-120, 2012. Disponível em: https://www.agb.org.br/publicacoes/index.php/terralivre/article/view/462. Acesso em: 27 de jun. de 2016.

SILVA, Tomaz Tadeu da. Teoria do currículo. In: SILVA, Tomaz Tadeu da (org.). Documentos de identidade: uma introdução às teorias do currículo. Belo Horizonte: Autêntica, 1999. p. 11-17.

SOUZA, Camila Vianna de. As práticas socioespaciais urbanas dos estudantes da EJA do município de Duque de Caxias - RJ. 2017. Dissertação (Mestrado em Geografia) Programa de Pós-Graduação em Geografia, Faculdade de Formação de Professores da Universidade do Estado do Rio de Janeiro, São Gonçalo, 2017.

TOMITA, Luzia Mitiko Saito. Ensino de geografia: aprendizagem significativa por meio de mapas conceituais. 2009. Tese (Doutorado em Geografia) - Programa de Pós-Graduação em Geografia Física, Departamento de Geografia, Faculdade de Filosofia, Letras e Ciências Humanas, Universidade de São Paulo, São Paulo, 2009. 